\title{
REFLEXÕES SOBRE VIOLÊNCIA DE GÊNERO A PARTIR DO FILME PRECIOSA
}

REFLECTIONS ON GENDER VIOLENCE FROM PRECIOUS

Érico Douglas Vieira ${ }^{1}$

\begin{abstract}
RESUMO
Através deste trabalho de natureza teórica, fizemos uma análise do filme Preciosa descrevendo os mecanismos de poder presentes nas relações familiares. As teorias feministas de gênero demonstram a construção social dos papéis que encerram homens e mulheres em essências naturalizadas. Esta construção social de gênero fomenta a violência de gênero, termo que amplia as noções de violência doméstica e intrafamiliar. O filme demonstra que a família nem sempre é o lugar de proteção e afeto e que a relação de suporte e respeito da professora com a protagonista aumentaram as possibilidades existenciais de Preciosa. Além de questionar que a anatomia não é o destino, as teorias de gênero buscam uma transformação das relações de gênero para vínculos mais igualitários na dimensão do poder. Seriam funções políticas da ciência o questionamento dos estereótipos de gênero e a luta para que os direitos humanos não sejam violados.
\end{abstract}

Palavras-chave: Violência; Teorias de Gênero; Preciosa.

\footnotetext{
${ }^{1}$ Psicólogo, Psicodramatista, Mestre em Psicologia, Doutorando em Psicologia. Professor Assistente do Curso de Psicologia da Universidade Federal de Goiás - Campus Jataí. E-mail: ericopsi@yahoo.com.br
} 


\begin{abstract}
Through this theoretical work, we did an analysis of the film Precious describing the mechanisms of power present in family relationships. Feminist theories of gender demonstrate the social construction of roles in wich men and women remains naturalized essences. This social construction of gender fosters gender violence, a term that extends the concepts of domestic violence within the family. The film demonstrates that the family is not always the place of protection and love, and the relationship of support and respect the teacher with the protagonist increased Precious existential possibilities. Besides questioning the anatomy is not destiny, gender theories seek a transformation of gender relations more equal ties to the dimension of power. Political functions of science would be the questioning of gender stereotypes and the struggle for human rights are not violated.
\end{abstract}

Key-words: Violence; Theories of gender; Precious.

\title{
Introdução
}

Este artigo pretende realizar uma análise da questão da violência de gênero a partir do filme Preciosa - Uma História de Esperança de 2009 (EUA), de direção de Lee Daniels. O filme abre possibilidades de análise dos processos de coisificação e de dominação que são alimentados por hierarquias de gênero. Nesta perspectiva, podem-se questionar naturalizações, hierarquias e poder existentes nas relações interpessoais. O filme parece-nos relevante por mostrar um drama de uma adolescente de dezesseis anos que corresponde a um triste retrato do que ocorre com inúmeras outras crianças e adolescentes.

Primeiramente, faremos uma breve descrição do filme trazendo uma reflexão sobre os processos de coisificação e dominação que podem estar presentes em relações familiares. A partir do filme, temos como objetivo apresentar algumas perspectivas teóricas sobre as 
relações de gênero bem como sobre a violência de gênero. Pretende-se, através deste trabalho, apresentar a evolução da compreensão da violência doméstica ou da violência contra a mulher para o conceito de violência de gênero bem como discutir o conceito de gênero no âmbito das teorias feministas. Ainda buscamos compreender o ciclo da violência e o processo de cronificação.

\section{A violência retratada em Preciosa}

A protagonista do filme Claireece Precious Jones, conhecida como Preciosa tem dezesseis anos, é obesa, negra, pobre e semi-analfabeta, vivendo situações extremas de abuso e violência dentro de casa. Sua mãe comete repetidos atos de violências física e psicológica: ela arremessa objetos, diz que Preciosa nunca será capaz de ser alguém na vida, força Preciosa a comer grandes quantidades de comida e permite que seu companheiro, o pai de Preciosa, abuse dela sexualmente. Preciosa já tinha um filho fruto destes estupros e, no momento retratado pela trama, ela está grávida do segundo filho.

Antes de iniciar o filme, uma frase é veiculada: "Tudo é uma dádiva do universo". Frase que contrasta com o que vem a seguir. Na primeira cena, Preciosa se imagina recebendo um lenço vermelho de uma mulher vestida como se fosse uma fada madrinha. Preciosa carrega consigo um lenço vermelho em quase todo o filme. Talvez o lenço simbolize a esperança que ela tinha de sair de uma vida opressiva. Começa, então, a trama, retratando a casa de Preciosa com cenas nas quais ela sofre inúmeros atos de violência vindos dos pais. Nestas cenas com cores escuras e embaçadas, a atmosfera é densa, opressiva, as cortinas da casa estão sempre fechadas deixando transparecer um contexto de isolamento no qual a violência e a coisificação do outro não têm freio. Uma sequência de cenas fortes: Preciosa está cozinhando de costas para a mãe e esta lhe arremessa um objeto pesado na cabeça, sem motivo algum. Ela cai no chão e se lembra de uma cena no qual o pai, com o corpo suado, a estupra dizendo: "Papai te ama". Um detalhe importante mostra a mãe assistindo o estupro da 
porta do quarto sem nada fazer. Em todos os momentos insuportáveis como este, Preciosa se imagina em cenas grandiosas, nas quais ela é uma celebridade. Neste momento, por exemplo, ela se imagina uma estrela de cinema desfilando num tapete vermelho, sendo assediada por fotógrafos e repórteres. Ela se transporta para uma situação na qual tem importância, é reconhecida e admirada pelas pessoas como forma de suportar a realidade na qual ela é apenas um objeto para satisfação dos desejos dos outros.

\section{Perspectivas teóricas sobre a violência de gênero}

Para realizar uma análise da violência de gênero, utilizamos uma perspectiva de gênero que nos permite questionar naturalizações, hierarquias e poder nas relações interpessoais. A perspectiva de gênero é importante nesta análise porque permite entender como as relações de poder dentro da família podem transformar diferenças de gênero e geração em relações assimétricas com fins de dominação e exploração (ARAÚJO, 2002). Escapa do escopo deste trabalho uma análise das diversas correntes feministas ou de gênero. Adota-se a perspectiva de gênero como uma construção social, um sistema de significados que se constrói e se sistematiza nas relações e que determina o acesso ao poder. $\mathrm{O}$ gênero não existe nas pessoas, não é um atributo individual de personalidade, mas existe nas relações sociais (NOGUEIRA, 2001).

É preciso enfatizar que gênero é diferente de sexo - sexo feminino e sexo masculino têm relação direta com a biologia, demarcando essências e sugerindo que seriam marcas imutáveis da pessoa. De acordo com o "sexo" que nascemos, somos alvo de uma série de expectativas de como devemos nos comportar e como devem ser os rumos de nossa vida. Em cima de uma diferença anatômica entre homens e mulheres, que seria a capacidade de procriação, desenvolveram-se, histórica e socialmente, hierarquias e desigualdades. Caberia à mulher as atividades de alguma forma associadas à reprodução como os cuidados domésticos com a casa e com os filhos. A mulher é socializada de forma a sentir-se responsável pela 
família e pelos afazeres domésticos e sua identidade é definida a partir das relações familiares (BRUSCHINI \& SARTI, 1990).

No entanto, importantes transformações começaram a ocorrer nas relações de gênero. Com a substituição da força humana pelas máquinas, as mulheres passaram a ter o mesmo potencial de trabalho dos homens. Além disso, com a expansão da sociedade de consumo, surgiu a necessidade de aumentar a renda familiar. As mulheres passaram a ter uma maior qualificação profissional e aumentou a anseio pela realização pessoal para além do mundo doméstico. Desta forma, assistimos a um aumento significativo da mulher no mercado de trabalho (BRUSCHINI \& SARTI, 1990). Somado ao advento dos métodos contraceptivos, que permitiu a separação da vida reprodutiva e da vida sexual, as mulheres passaram a questionar a condição de submissão a que estavam expostas. A busca por uma maior igualdade e a conseqüente transformação das relações de gênero foi o foco do movimento feminista que florescia na década de 60.

Nos primórdios dos estudos de gênero na década de 60 a frase de Simone de Beavoir, "ninguém nasce mulher, torna-se mulher", influenciou as buscas de tentar retirar o caráter de essência do gênero. Desta forma, é preciso aprender a ser mulher, uma vez que o feminino não é determinado pela biologia, e sim construído pela sociedade (BRUSCHINI \& SARTI, 1990). Este é grande mote dos estudos de gênero, que deixa claro atualmente que ser mulher ou homem é uma construção social e não um dado biológico e imutável. A anatomia não é o destino. Hoje se pode perguntar que tipo de homem ou que tipo de mulher se quer ser. Ser mulher e ser mãe não se encontram necessariamente, ou seja, a mulher não tem mais a obrigação de ser mãe para realizar uma suposta "essência" feminina. É preciso fazer a ressalva que houve transformações nas relações de gênero, mas ainda há permanências. Saffioti (2001) considera que o patriarcado com a conseqüente dominação masculina ainda permaneça, embora de forma mitigada. De acordo com a autora, as mulheres ainda são sujeitos com menor prestígio na sociedade e os homens ainda utilizam-se da violência para exercerem seu poder sobre as mulheres. Para ilustrar este aspecto, basta assistirmos aos noticiários nos quais veiculam diariamente mulheres sendo assassinadas por seus companheiros. 
Os discursos de gênero disponíveis socialmente colocam o masculino e o feminino como pólos opostos, enfatizam as diferenças e as colocam como essências. Para enfatizar as diferenças entre homens e mulheres é preciso que as semelhanças sejam camufladas. Desta forma, homens e mulheres são socializados de modo a terem uma percepção de que o outro gênero é muito diferente e estranho. Este sistema de gênero origina duas formas de discriminação/subordinação: o sexismo e a homofobia, conforme nos aponta Smigay (2002):

Nas sociedades onde homens, tanto coletivamente quanto individualmente, dominam as mulheres, o sexismo organiza a dominação das mulheres e a homofobia vem selar a coesão entre os dominantes. Tanto o sexismo quanto a homofobia estruturam o medo de abandonar as atribuições de seu grupo sexual (SMIGAY, 2002, p. 38).

Além de construir scripts diferentes para homens e mulheres, que funcionam como essências, o sistema de gênero pressupõe uma visão heterossexuada do mundo, no qual as relações erótico-afetivas entre homens e mulheres são vistas como naturais. As outras sexualidades, homossexuais, bissexuais, transexuais, são "toleradas"como diferentes, na melhor das hipóteses (WELZER-LANG, 2001).

Diante deste quadro os homens são categorias que possuem privilégios materiais, culturais e simbólicos. Para se ter uma leitura mais crítica sobre as questões de gênero, não podemos mencionar apenas os diferentes papéis ou scripts prescritos para homens e mulheres, mas as hierarquias e diferenças de poder que colocam a mulher e outros sujeitos numa posição de assujeitamento. Estes outros sujeitos que ocupam uma posição menos favorecida simbolicamente são os homossexuais, bissexuais, transexuais e também as crianças e adolescentes. Seriam todos os assujeitados que, em determinados contextos, estão numa posição considerada feminilizada. De acordo com esta lógica, Smigay (2002) propõe o conceito de violência de gênero:

Como um tipo de violência em que a questão do poder, desigual entre os envolvidos, é a marca. Poder este diferenciado segundo o pertencimento de gênero - mulheres, homens não-viris, homens e mulheres que optam por práticas homoeróticas, crianças e 
adolescentes; são estes os objetos privilegiados desta violência homofóbica/sexista (p. $37)$.

De acordo com Saffioti (2001) a violência de gênero está associada ao patriarcado que seria um sistema de dominação do patriarca sobre outras categorias sociais como mulheres, crianças e adolescentes de ambos os sexos. Em outro trabalho, a autora define patriarcado como "um conjunto de relações sociais que tem uma base material e no qual há relações hierárquicas entre homens, e solidariedade entre eles, que os habilitam a controlar as mulheres. É o sistema masculino de opressão das mulheres" (SAFFIOTI, 2000, p. 13).

Os homens, no exercício da função de patriarca, teriam o poder de determinar as condutas das categorias sociais assujeitadas e punir o que julgam como desvio. O patriarcado seria, portanto, um sistema de dominação/exploração das mulheres no qual os homens possuem autorização de utilizarem de violência para manter a ordem que garante seus privilégios. Ainda há patriarcado, embora tenha sido mitigado. Quando ainda assistimos à violência masculina contra as mulheres, à discriminação salarial das trabalhadoras, à marginalização da mulher dos importantes papéis econômicos e políticos, ao controle da sexualidade e da capacidade reprodutiva da mulher (SAFFIOTI, 2000). Poderíamos entender que o mundo ainda é feito para os homens.

Ao contrário do que possa parecer, as mulheres sempre reagem de alguma forma à violência sofrida. Saffioti (2001) defende que não devemos continuar utilizando o termo "vítima" para mulheres que estão em situação de violência. Segundo a autora, as mulheres sempre utilizam mecanismos de resistência e sempre reagem contra o agressor de diferentes maneiras.

É importante a diferenciação entre conceituações de violência. Teríamos a violência intrafamiliar na qual o alvo são membros da família nuclear e extensa e não se restringe ao território físico do domicílio. A violência doméstica atinge vítimas sem parentesco com o agressor. Um exemplo freqüente são as empregadas domésticas que podem ser vítimas de 
violência sexual por parte de seus patrões. A violência doméstica ainda incluiria a violência praticada pelas mulheres contra crianças e adolescentes. O espaço doméstica pode ser entendido não somente pelo seu aspecto físico, mas também pelo aspecto simbólico. Homens podem continuar exercendo seu poder sobre as mulheres mesmo que estas já estejam separadas deles. Diante do exposto, percebe-se que a violência intrafamiliar pode sobrepor-se a violência doméstica. No entanto, é necessária a distinção quando estudamos casos de abusos sexuais incestuosos, nos quais o agressor tem um laço de parentesco e de confiança com a vítima (SAFFIOTI, 2001). O fato de que há um vínculo de confiança entre agressor e vítima traz importantes implicações nas conseqüências da violência. Ainda teríamos o termo violência contra a mulher que, obviamente, seria as agressões sofridas pelas mulheres por seus companheiros. A violência de gênero seria o conceito mais amplo, englobando mulheres, crianças, adolescentes de ambos os sexos e pessoas que não possuem uma orientação sexual heterocentrada (SMIGAY, 2002).

A violência de gênero deve ser entendida dentro de um contexto que permite papéis diferenciados e desigualdades de poder entre sujeitos dependendo do lugar social que ocupam. Desta forma, um homem branco, heterossexual, de alto poder aquisitivo, por exemplo, gozaria de muitos privilégios materiais e simbólicos em nossa sociedade.

Welzer-Lang (2001) analisou a construção das masculinidades demonstrando que o masculino se constrói através da violência. O autor conceitua a "Casa dos homens" que seriam lugares exclusivamente masculinos onde os pequenos homens são levados a pensar que para ser um verdadeiro homem devem combater quaisquer aspectos que possa ser associado ao mundo das mulheres. Os mais velhos corrigem e modelam os mais novos que buscam o acesso à virilidade. $\mathrm{O}$ pequeno homem se distancia do mundo das mulheres e das crianças e passa a conviver em lugares ocupados somente por homens. No entanto, ao lado do prazer em estar com os outros homens, há também muito sofrimento que não pode ser expresso. Os pequenos homens devem seguir os códigos dos mais velhos, devem endurecer os corpos, imitar os gestos, jogar futebol tão bem quanto os outros. Esta aprendizagem acompanhada de dor refere-se a uma violência dirigida contra os pequenos homens. Portanto, os homens aprendem a ser homens através da violência que é primeiramente dirigida contra 
eles mesmos. Primeiramente os homens empreendem uma guerra contra eles mesmos, posteriormente esta guerra é dirigida com os outros (WELZER-LANG, 2001). A socialização para a violência fomenta as violências cotidianas dos homens contra mulheres, crianças, adolescentes e outros sujeitos sociais não-viris.

\section{Pensando saídas}

A violência de gênero deve ser entendida dentro de um contexto que permite papéis diferenciados e desigualdades de poder entre sujeitos dependendo do lugar social que ocupam. Desta forma, um homem branco, heterossexual, de alto poder aquisitivo, por exemplo, gozaria de muitos privilégios materiais e simbólicos em nossa sociedade. Pensando na protagonista do filme, ela ocuparia uma posição bastante vulnerável por ser negra, mulher, pobre e obesa - o ideal de um corpo magro é cada vez mais valorizado.

O conceito de violência de Chauí (1985 apud ARAÚJO, 2002) refere-se a uma relação de forças caracterizada num pólo pela dominação e no outro pela coisificação. Seria a transformação de uma diferença e de uma assimetria numa relação de desigualdade com fins de exploração e opressão. Seria uma ação que trata um ser humano como coisa e não como sujeito. No fim do filme, Preciosa e sua mãe têm uma reunião com a assistente social. A mãe de Preciosa quer que ela volte a morar com ela, dizendo: "Eles pertencem a mim", referindose à Preciosa e seus dois filhos. Fica bem nítido o processo de coisificação de Preciosa nesta relação com a mãe. Além da permissão do abuso, a mãe usa Preciosa e seus filhos - que estão sob sua tutela até então - para receber auxílio-família do governo e não precisar trabalhar. Nesta cena a mãe relata o primeiro abuso sexual do pai quando Preciosa tinha três anos. A mãe diz que odiou Preciosa porque o homem dela queria a filha e não ela: "A culpa é da vadia porque deixou o meu homem possuí-la”. Nesta cena, além de tentar culpar a filha pelos abusos sofridos, a mãe insinua que talvez Preciosa não esteja falando a verdade. Em relação à permissão do abuso por parte da mãe, Araújo (2002) caracteriza tal processo como o desmentido materno: 
Negar, desmentir a filha ou culpá-la pela sedução é uma forma de suportar o impacto da violência, da desilusão e da frustração diante da ameaça de desmoronamento da unidade familiar e conjugal. Pode acontecer também estar a negação da mãe relacionada com uma cumplicidade silenciosa, muito freqüente em casais com conflitos sexuais, onde a criança ocupa um lugar (função sexual) que não é dela, amenizando assim o conflito conjugal. Em qualquer das situações, o desmentido materno, a afirmação de que nada aconteceu, é o pior que pode acontecer a uma criança que denuncia o abuso sexual (p. 07).

A autora supracitada caracteriza algumas conseqüências do abuso sexual: sentimentos de vergonha, medo, desamparo, tristeza, baixa auto estima. Em uma cena, Preciosa anda pelas ruas e alguns de seus pensamentos vão sendo retratados: "Às vezes queria estar morta"; "me sinto como uma gordura preta e feia que precisa ser removida". Logo em seguida, um grupo de rapazes zomba muito dela por ela ser gorda e um deles a empurra no chão. Quando ela chega em casa, se olha no espelho e no reflexo se vê como uma mulher branca, loira e magra.

Então, começa um novo dia. Preciosa pensa: “Ontem eu chorei. É por isso que Deus, seja lá quem for, faz outros dias”. A partir daí uma mudança se inicia quando Preciosa começa a frequentar a escola alternativa. Quando ela entra para a sala de aula no primeiro dia, a cena fica iluminada com cores vibrantes em contraste com atmosfera opressiva de casa. Preciosa se apresenta e diz que é a primeira vez que fala numa sala de aula e a professora Blu Rain pergunta a ela como se sente. Preciosa responde: “Isto me faz sentir aqui”. A relação da professora Rain com Preciosa é de extrema valia para que esta comece a se fortalecer e a pensar em novas perspectivas para a sua vida. Preciosa diz: "Minha mãe diz que a escola não presta. Ela está enganada. Eu estou aprendendo". Preciosa pensa nos filhos e começa a ter vontade de ser uma boa mãe e transmitir coisas positivas para eles. Ela vê na TV um discurso de Martin Luter King ("Eu ainda tenho um sonho”) e diz que tem vontade de ensinar isto aos 
filhos. Enquanto está grávida do segundo filho diz: "Ouça bebê, a mamãe não é idiota". Preciosa consegue aos poucos se libertar da relação de dominação com a mãe. Depois que nasce seu segundo filho, ela enfrenta a mãe e sai de casa, passando uma temporada na casa da professora Rain. Esta mora com sua companheira e, quando Preciosa é acolhida pelas duas pensa: "Porque pessoas que mal me conhecem são mais legais comigo do que meus pais? Mamãe diz que os homossexuais são gente ruim. Mamãe: os homossexuais não me violentaram!"

Depois Preciosa vai para um abrigo dizendo que lá era um meio termo entre a velha vida e a outra vida onde queria estar. Ela ganha um prêmio de alfabetização. Em seguida, fica sabendo que o pai morreu de Aids, ela faz os exames e descobre que é soropositiva. Ela diz que morrer não a preocupa e que está preocupada em como vai criar os seus filhos. Há uma próxima cena na qual ela passa o seu lenço vermelho para uma menina que morava no mesmo prédio que ela e que estava com marcas de agressão. Na última cena, Preciosa diz a assistente social que esta não pode dar conta dela. Ela sai andando pelas ruas com seus dois filhos, com um semblante confiante. O filme termina com a dedicatória: "Para todas as garotas preciosas do mundo".

\section{Considerações finais}

O presente trabalho teve como objetivo realizar uma leitura da questão da violência de gênero a partir do filme Preciosa, que nos abre possibilidades de análise dos processos de dominação e coisificação que podem estar presentes em relações de intimidade como as relações familiares.

A partir do filme, fizemos uma breve descrição de algumas abordagens teóricas sobre a construção das teorias de gênero no âmbito do movimento feminista. Apresentamos a evolução dos conceitos de violência doméstica e intrafamiliar para o conceito de violência de gênero, bem como a diferenciação entre eles. 
Podem-se perceber as diversas conseqüências da violência que ocorrem em relações de intimidade. A personagem do filme Preciosa sofre inúmeras agressões físicas e verbais que afetam o seu conceito de si mesma, fazendo com que ela experimentasse uma falta de sentido na vida. As fantasias nas quais ela se imaginava em cenas de grandeza como uma pessoa famosa e assediada pelos fãs, representava um esteio imaginário de sobrevivência em face da miséria relacional na qual estava imersa. Através desta estratégia de se imaginar como uma celebridade pôde suportar os momentos mais dolorosos de opressão. Somente com o advento de um novo vínculo com a professora Blu Rain, Preciosa consegue uma nova vinculação com a existência. A professora a incentivava a crescer como pessoa e acreditava em seu potencial. É o afeto que pode vir fora das relações familiares. A família, numa concepção idealizada, deveria ser o espaço de proteção e afeto. No entanto, pode ser o lugar no qual os direitos humanos são violados nas formas mais cruéis, como retratado no filme.

As teorias de gênero pretendem não somente descrever a construção social dos mecanismos de gênero, que encerram homens e mulheres em scripts predeterminados. Além de questionar que a anatomia não é o destino, as teorias de gênero buscam uma transformação das relações de gênero para vínculos mais igualitários na dimensão do poder. Se tivéssemos relações mais equânimes, as garotas preciosas do mundo seriam, de fato, preciosas.

\section{Referências bibliográficas}

ARAÚJO, Maria de Fátima. Violência e abuso sexual na família. Psicologia em Estudos. Vol. 7, n.2, 2002.

BRUSCHINI, Cristina \& SARTI, Cynthia. Relações de Gênero. Gênero e Geração de Renda, Programa UNICEF: São Paulo, 1990.

NOGUEIRA, Conceição. (2001). Feminismo e discurso de gênero na psicologia social. Revista Psicologia \& Sociedade, vol 3, n.1, 2001. 
SAFFIOTI, Heleieth. Gênero e Patriarcado: São Paulo, 2000. mimeo, versão não publicada, sob autorização provisória da autora.

SAFFIOTI, Heleieth . Contribuições feministas para o estudo da violência de gênero. Cadernos Pagu: Campinas, n. 16, 2001.

SMIGAY, Karin Ellen. Sexismo, homofobia e outras expressões correlatas de violência: desafios para a psicologia política. Psicologia em Revista: Belo Horizonte, v.8, n.11, 2002.

WELZER-LANG, Daniel. A construção do masculino: dominação das mulheres e homofobia. Revista Estudos Feministas: Florianópolis， v. 9, n. 2， 2001. 